\title{
Targeting a coatomer protein complex-I gene via RNA interference results in effective lethality in the pollen beetle Brassicogethes aeneus
}

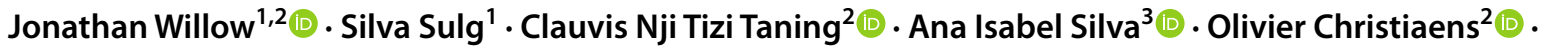

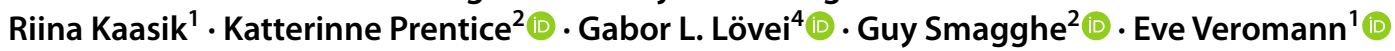

Received: 4 March 2020 / Revised: 6 July 2020 / Accepted: 24 September 2020 / Published online: 16 November 2020

(c) The Author(s) 2020

\begin{abstract}
The pollen beetle Brassicogethes aeneus is a serious pest of oilseed rape (Brassica napus) in Europe. Management of this pest has grown difficult due to B. aeneus's development of resistance to pyrethroid insecticides, as well as the pressure to establish control strategies that minimise the impact on nontarget organisms. RNA interference represents a nucleotide sequence-based, and thus potentially species-specific, approach to agricultural pest control. The present study examined the efficacy of targeting the coatomer gene coatomer subunit alpha $(\alpha C O P)$, via both microinjection and dietary exposure to exogenous complementary dsRNA, on $\alpha C O P$-silencing and subsequent mortality in B. aeneus. Beetles injected with dsRNA targeting $\alpha C O P$ (at $0.14 \mu \mathrm{g} / \mathrm{mg}$ ) showed $88 \%$ and $100 \%$ mortality at 6 and 10 days post-injection, respectively; where by the same time after dietary exposure, $43 \%-89 \%$ mortality was observed in the $3 \mu \mathrm{g}$ dsRNA/ $\mu \mathrm{L}$ treatment, though the effect was concentration-dependent. Thus, the effect was significant for both delivery routes. In working towards RNA-based management of $B$. aeneus, future studies should include $\alpha C O P$ as a target of interest.
\end{abstract}

Keywords RNAi $\cdot$ Brassicogethes aeneus $\cdot$ Meligethes aeneus $\cdot$ Oilseed rape $\cdot$ Rapeseed $\cdot$ COPI $\cdot$ Biopesticide $\cdot$ Coleoptera

\section{Key message}

Communicated by M. Traugott .

Guy Smagghe and Eve Veromann have contributed equally to this work.

Electronic supplementary material The online version of this article (https://doi.org/10.1007/s10340-020-01288-6) contains supplementary material, which is available to authorised users.

Jonathan Willow

jonathan@emu.ee

$\triangle$ Eve Veromann

eve.veromann@emu.ee

1 Chair of Plant Health, Institute of Agricultural and Environmental Sciences, Estonian University of Life Sciences, Tartu, Estonia

2 Laboratory of Agrozoology, Department of Plants and Crops, Faculty of Bioscience Engineering, Ghent University, Ghent, Belgium

3 Faculty of Health, Medicine and Life Sciences, School of Mental Health and Neuroscience, Maastricht University, Maastricht, The Netherlands

4 Department of Agroecology, Flakkebjerg Research Centre, Aarhus University, Slagelse, Denmark
- We examined RNAi efficacy, targeting the coatomer gene $\alpha C O P$ in Brassicogethes aeneus, via both microinjection and feeding of dsRNA.

- Our work represents the first demonstration of highly significant mortality in a pest insect through targeting a coatomer protein complex-I gene via feeding.

- Our work further indicates $B$. aeneus's sensitivity to naked dsRNA.

- Future RNAi studies in this important pest species and other pest insects should include $\alpha C O P$ as a potential target of interest.

\section{Introduction}

The pollen beetle Brassicogethes aeneus Fabricius (Coleoptera: Nitidulidae; formerly Meligethes aeneus) is Europe's primary pest of oilseed rape (Brassica napus L.). After overwintering, adult $B$. aeneus feed on pollen and nectar of a variety of blooming plants (e.g., Rosaceae, Asteraceae, 
Lamiaceae, etc.), and subsequently colonise cruciferous (Brassicaceae) plants, where they acquire nutrients from buds and open flowers, mate, and oviposit into buds. Upon emergence from eggs, larvae feed on pollen within buds, eventually obtaining their nutrients from open flowers, followed by pupation in the soil under their host plant (see review by Mauchline et al. (2018)).

Synthetic insecticides are currently the standard method for B. aeneus control (Zhang et al. 2017; Zamojska 2017; Raimets et al. 2020). Consequently, B. aeneus has developed high levels of resistance to pyrethroid insecticides in several areas across Europe (Slater et al. 2011; Heimbach and Müller 2013; Zamojska 2017; Stará and Kocourek 2018; Kaiser et al. 2018). While neonicotinoid insecticides are also being applied in B. aeneus management (Seidenglanz et al. 2017; Kaiser et al. 2018), exposure to neonicotinoids has shown negative effects on a wide range of nontarget organisms (Gibbons et al. 2015; Pisa et al. 2017; Willow et al. 2019; Berheim et al. 2019; Calvo-Agudo et al. 2019; Wu et al. 2019). For example, in oilseed rape agroecosystems, nontarget organisms negatively affected by thiacloprid applications could include economically important parasitoids of $B$. aeneus, given that laboratory studies have demonstrated the detrimental effect of thiacloprid on other parasitoid wasps (Sugiyama et al. 2011; Jans 2012; Willow et al. 2019). Notably, among a European Union (EU)-wide ban on the outdoor use of three other neonicotinoids, thiacloprid is currently banned from both outdoor and greenhouse use in France, with an EU-wide ban on the outdoor use of thiacloprid tentative for implementation by 3 August 2020, with maximum grace period up to 3 February 2021 (European Commission 2018), based on the European Food Safety Authority's (EFSA) peer review of the risk assessment of thiacloprid (Abdourahime et al. 2019). Thus, there is urgent need for developing pest control strategies that minimise the impact on nontarget organisms, for effective and ecologically sustainable $B$. aeneus management.

The process of double-stranded ribonucleic acid (dsRNA)-mediated gene silencing, also known as RNA interference (RNAi), represents a potentially species-specific approach to agricultural pest control (Huvenne and Smagghe 2010; Taning et al. 2019; Bramlett et al. 2019; Zhu and Palli 2020; Mezzetti et al. 2020). In brief, exogenous dsRNA is taken up by the target species. Once the dsRNA enters the cell cytoplasm, the ribonuclease III enzyme Dicer- 2 cleaves this dsRNA into double-stranded segments approximately 21 nucleotides in length, called small interfering RNAs (siRNAs). A multiprotein complex, with the endoribonuclease Argonaute 2 as its catalytic centre, binds to one strand (the guide strand) of an siRNA, forming the RNA-induced silencing complex (RISC), and results in the degradation of the opposite (the passenger strand) siRNA strand. The guided RISC becomes bound to complementary endogenous messenger RNA (mRNA), and the RISC cleaves this mRNA, thus inhibiting its decoding in the ribosome and, in turn, subsequent protein synthesis (Bramlett et al. 2019).

Recently, all major RNAi pathway genes were identified in the B. aeneus transcriptome (Knorr et al. 2018). Genes and associated proteins thought to be necessary for systemic RNAi were also identified by the same authors. These authors were the first to report RNAi in B. aeneus via dietary exposure to exogenous dsRNA, and showed the efficacy of dsRNAs targeting the protein-coding genes nucampholin ( $\mathrm{ncm}$ ), Ras opposite (Rop), RNA polymerase II 140kD subunit (RpII140), and dre4 (dre4). These target genes were chosen because they were orthologous to the four most RNAi-sensitive target genes from western corn rootworm (Diabrotica virgifera LeConte) diet bioassays conducted by the same authors (Knorr et al. 2018). However, before considering field use of dsRNA-based crop protection products in oilseed rape agroecosystems, it remains critical to carefully select additional RNAi target genes in B. aeneus and determine the effect of their inactivation, especially during this very early stage of developing an RNAi technique for this species.

One target gene of interest, coatomer subunit alpha $(\alpha C O P)$, encodes the coatomer subunit alpha $(\alpha \mathrm{COP})$ protein. The $\alpha \mathrm{COP}$ protein is a subunit of coatomer protein complex-I (COPI), which is involved in vesicular transport of proteins between the endoplasmic reticulum and Golgi apparatus, as well as possibly maintaining distribution of proteins within the Golgi stack (Beck et al. 2009). The COPI coat adhering to intracellular vesicles also interacts with cell division control protein 42 homolog (CDC42), a regulator of the cytoskeletal motor protein dyenin, which transports various cellular cargo (Beck et al. 2009). A large-scale RNAi screening revealed COPI's additional role in maintaining lipid homeostasis (Beller et al. 2008). Finally, knockdown of COPI subunits results in failure of cytokinesis, via preventing the accumulation of vital proteins and lipid components at the cleavage furrow, as well as reducing the number of overlapping microtubules at the central spindle, a key regulating centre for cytokinesis (Kitazawa et al. 2012). Thus, $\alpha C O P$ was chosen as the RNAi target of interest in the present study, based on the expectation that its downregulation can be lethal. Indeed, previous dsRNA-microinjection experiments suggest the potential efficacy of targeting $\alpha C O P$ in larvae of the African sweetpotato weevils Cylas brunneus Fabricius (Christiaens et al. 2016) and C. puncticollis Boheman (Prentice et al. 2017). However, we are not aware of any study to date that has thoroughly examined, via dietary exposure, the effect of targeting $\alpha C O P$ in a coleopteran pest.

The present study examined the efficacy, via both microinjection and dietary exposure, of dsRNA targeting $\alpha C O P$ in $B$. aeneus. We also examined its potential dsRNA-concentration-dependent RNAi effect through dietary exposure. 
Due to $\alpha C O P$ 's various biological functions, we expected this gene to be an effective RNAi target in B. aeneus, and furthermore expected to observe dsRNA-concentrationdependent reductions in survival of $B$. aeneus when targeting $\alpha C O P$.

\section{Materials and methods}

\section{dsRNA products}

The gene $\alpha C O P$ was detected in the transcriptome of $B$. aeneus (Zimmer et al. 2014) [available in the GenBank database (National Centre for Biotechnology Information$\mathrm{NCBI}$ ] via BLAST analysis, using known $\alpha C O P$ sequences from other insect species. In order to avoid cross-silencing of other genes in B. aeneus, a selected region (222 bp; Online Resource 1) from the $B$. aeneus $\alpha C O P$ coding sequence was screened for cross-homologies within the $B$. aeneus transcriptome using BLAST analysis to ensure that there were no shared fragment identities greater than 19 nucleotides in length. The chosen $\alpha C O P$ region was additionally screened against all bee species with available genome data in NCBI.

The chosen $\alpha C O P$ region, as well as a 455 bp sequence from the green fluorescent protein ( $g f p$ ) gene (Online Resource 1), was used as the basis for the in vitro synthesis of corresponding dsRNA products by AgroRNA (Genolution, Seoul, South Korea). The synthesised dsRNA products were shipped in distilled water at ambient temperature, and kept at $5 \pm 1{ }^{\circ} \mathrm{C}$ once received. Products used in this study included dsRNAs with sequences complementary to specific genes: $g f p$, which represented our control treatment, as it is not present in insects; and the target gene $\alpha C O P$. Treatments targeting the genes $g f p$ and $\alpha C O P$ are hereafter respectively referred to as dsGFP and ds $\alpha \mathrm{COP}$. The length and purity of the dsRNA products used were confirmed via gel electrophoresis (Online Resource 2).

\section{Insects}

Pollen beetles were collected from an untreated organic oilseed rape field $\left(58.37979^{\circ} \mathrm{N}, 26.66394^{\circ} \mathrm{E}\right)$ in the village of Kandiküla, Tartu County, Estonia. Beetles were kept in ventilated plastic containers and allowed to feed ad libitum on pollen of oilseed rape and dandelion (Taraxacum spp.) flowers. Oilseed rape flowers were collected from the same field where pollen beetles were collected, and dandelion flowers were collected from wildflower areas within and around the campus of the Estonian University of Life Sciences. All pollen beetles used in the study were identified as B. aeneus, using an identification guide by Kirk-Spriggs (1996), prior to their addition to the study.

\section{Experimental set-up: microinjection}

Ensured delivery of dsRNA into the haemolymph of $B$. aeneus was performed under a stereomicroscope using a microinjector (FemtoJet 4i, Eppendorf, Hamburg, Germany) and micromanipulator (Narishige, Tokyo, Japan) equipped with an injection needle prepared from glass capillary tubes. Twenty groups of ten randomly chosen $B$. aeneus adults were weighed (Sartorius Lab Instruments, Göttingen, Germany) in plastic vials in order to obtain an average weight per individual beetle $(1.4 \pm 0.1 \mathrm{mg})$. Prior to microinjection, beetles were anaesthetised with diethyl ether for $2 \mathrm{~min}$. Subsequently, they were individually placed on their dorsal surface upon a glass slide, and held in place by gently pressing a glass cover slip over their ventral abdominal surface. This gentle pressing resulted in the extension, and subsequent visualisation, of at least one of two intersegmental areas composed of arthrodial membrane (unsclerotised, soft and flexible cuticular surface), including the cervix (membrane separating head from thorax, i.e. neck) and a similar area separating thorax from abdomen.

For both treatments (dsGFP (control) and ds $\alpha \mathrm{COP}$ ), beetles were microinjected with $0.2 \mu \mathrm{L}$ of dsRNA solution at $1 \mu \mathrm{g}$ dsRNA/ $\mu \mathrm{L}$ (approximately $0.14 \mu \mathrm{g}$ dsRNA/mg). Approximately 15-20 beetles were injected per treatment, and after $24 \pm 1 \mathrm{~h}$, ten randomly chosen and fast moving (used as a proxy for health) individuals from both treatments were removed and placed into transparent, polystyrene, ventilated insect breeding dishes (diameter $10 \mathrm{~cm}$ x height $4 \mathrm{~cm}$ ) (SPL Life Sciences, Gyeonggi-do, South Korea), hereafter referred to as cages. This was replicated 4 times to obtain a total of 40 dsRNA-injected beetles per treatment. Another group of approximately 55-60 beetles was injected for each treatment, and after $24 \pm 1 \mathrm{~h}$ post-injection, 36 fast moving beetles per treatment were removed and used for analysis of gene expression via quantitative polymerase chain reaction (qPCR; three replicates of six beetles were analysed at 2 and $5 \mathrm{~d}$ post-injection; see Analysis of gene expression). Experimental set-up is illustrated in Fig. 1a.

Post-injection, beetles were placed in a growth chamber (Sanyo MLR-351H, Osaka, Japan) at $20 \pm 2{ }^{\circ} \mathrm{C}, 60 \% \mathrm{RH}$ and 16:8 h L:D cycle, allowed to feed ad libitum on oilseed rape pollen via laboratory-grown oilseed rape flowers, and were provisioned with a moist piece of cotton for access to drinking water. Fresh food and water were provided every $24 \pm 1 \mathrm{~h}$, when the previous day's food and water were removed from the cages. Survival and mobility were assessed every $24 \pm 1 \mathrm{~h}$ for $10 \mathrm{~d}$ post-injection, and comparisons between the dsGFP and ds $\alpha \mathrm{COP}$ treatment were statistically assessed using Fisher's exact test in R software v1.1.463 (R Foundation for Statistical Computing, Vienna, Austria). 


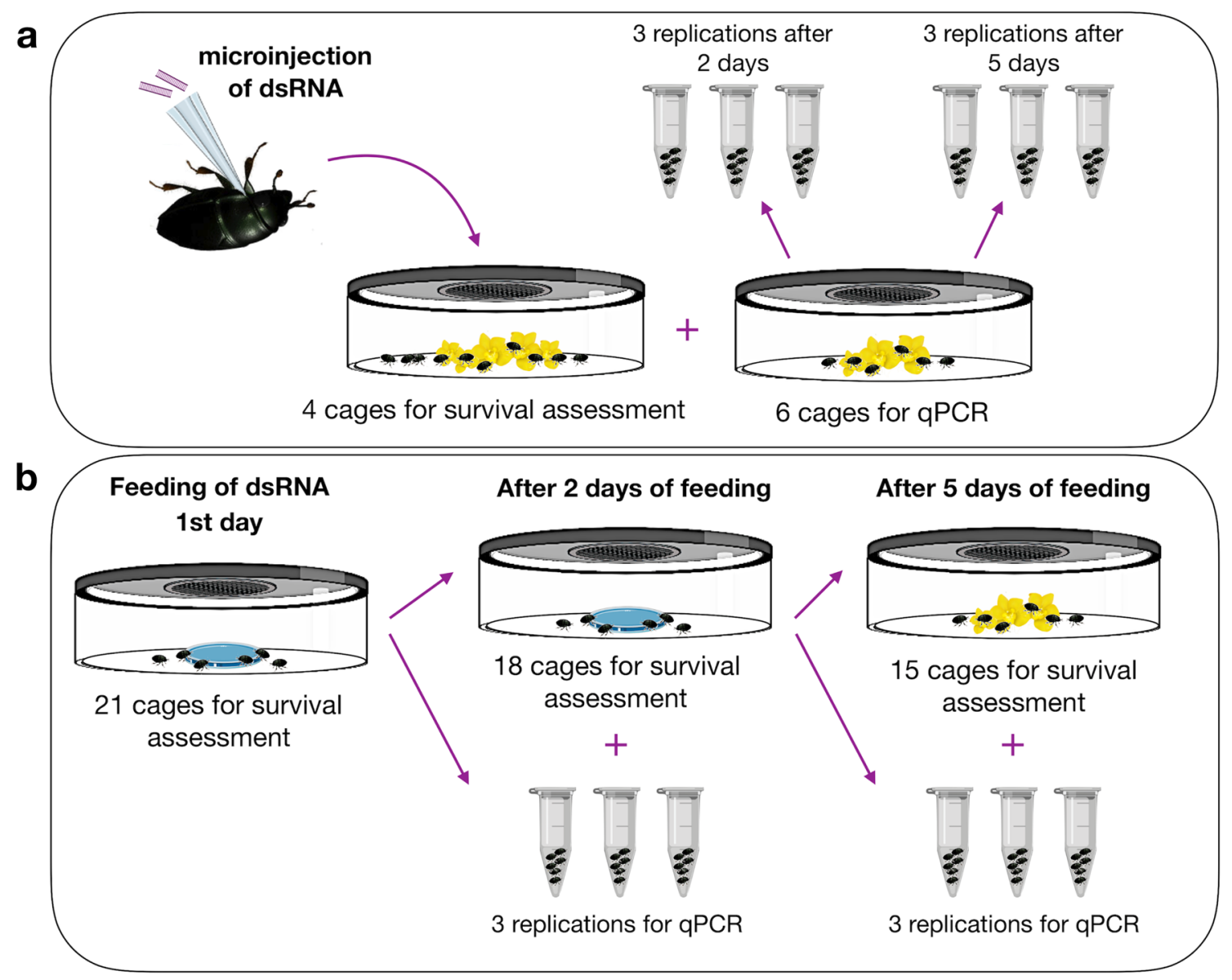

Fig.1 Experimental set-up for microinjection (a) and feeding (b) experiments, for each treatment. Microinjection experiment: $n=40$ (four replicates of ten beetles) per treatment for survival assessment; $n=3$ ( 3 replicates of 6 beetles) for each time-point of analysis within each treatment. Microinjected beetles fed ad libitum on pollen of oilseed rape flowers post-injection. Feeding experiment: $n=21$ (21

\section{Experimental set-up: feeding}

Brassicogethes aeneus were identified and placed into cages (described above), in groups of six randomly chosen and fast moving (used as a proxy for health) beetles per cage. We tested four treatments, including dsGFP and ds $\alpha$ COP each at both 1 and $3 \mu \mathrm{g}$ dsRNA/ $\mu \mathrm{L}$. Treatment solutions were $25 \%$ organic honey for nutrition; nuclease-free water was used to obtain the desired dsRNA concentrations; and bromophenol blue was added to allow confirmation of feeding (i.e. the presence of blue faeces in cages).

Each treatment was allocated 21 cages, each cage containing six beetles and one treatment source. The treatment source was a modified Eppendorf cap (removed from a $1.5 \mathrm{~mL}$ Eppendorf tube; hereafter referred to as cap) forming a basin, the height of which was reduced using a razorblade in order to allow the beetles to stand up and drink from the cap without having to sit upon the lip of the basin (which, cages of 6 beetles; days $0-2), 18$ (18 cages of 6 beetles; days 3-5) and 15 ( 15 cages of 6 beetles; days 6-19) per treatment; $n=3$ ( 3 replicates of 6 beetles) for each time-point of analysis within each treatment. In feeding experiment, beetles were fed dsRNA for $5 \mathrm{~d}$, followed by ad libitum feeding on pollen of oilseed rape flowers for the remaining during of survival assessment

according to preliminary observations, increased the chance of beetles falling into the treatment solution). Each cap held $100 \mu \mathrm{L}$ of treatment solution. Prior to pipetting dsRNA treatment solutions into the caps, treatment stocks were homogenised for approximately $5 \mathrm{~s}$ at $3200 \mathrm{rpm}$ (Vortex-Genie 2, Scientific Industries, Bohemia, New York, USA).

Once exposed to treatments, beetles were kept in the growth chamber at $20{ }^{\circ} \mathrm{C}, 60 \% \mathrm{RH}$ and 16:8 h L:D cycle. A new cap with freshly prepared treatment was provided to each cage every $24 \pm 1 \mathrm{~h}$, when the previous day's cap was removed. Survival and mobility were assessed every $24 \pm 1 \mathrm{~h}$ for $19 \mathrm{~d}$. Dead beetles were removed from cages daily.

After $2 \mathrm{~d}$ of allowing the beetles to feed on their respective treatments, three cages containing six live beetles, per treatment, were removed for analysis of relative gene expression via qPCR (see Analysis of gene expression), and thus 18 cages per treatment remained for survival/mobility assessment. A second removal for gene expression analysis 
occurred after $5 \mathrm{~d}$ of feeding on treatments, leaving 15 cages for mortality/mobility assessment per treatment. Experimental set-up is illustrated in Fig. $1 b$.

For the remainder of the experiment, beetles were allowed to feed ad libitum on oilseed rape pollen, via laboratorygrown oilseed rape flowers, and were provisioned with a moist piece of cotton for access to drinking water. Fresh food and water were provided every $24 \pm 1 \mathrm{~h}$, when the previous day's food and water were removed from the cages. Reductions in survival and mobility between ds $\alpha \mathrm{COP}$ treatments and their respective dsGFP controls, as well as between the two ds $\alpha$ COP treatments, were then statistically assessed in $\mathrm{R}$ software v1.1.463. Homogeneity of variance and normality of data distributions were examined using the Leveneand Shapiro-Wilk tests, respectively. Given that the data were overall not normally distributed, the nonparametric Kruskal-Wallis test was used as an alternative to ANOVA, followed by post hoc pairwise comparisons using the Wilcoxon rank-sums test.

\section{Analysis of relative gene expression}

Relative gene expression was measured using qPCR. Beetles analysed were removed from their cages at 2 and $5 \mathrm{~d}$ after first exposure to dsRNA treatments (see above). Treatment groups analysed for relative gene expression were six in total, including: those microinjected with dsGFP and ds $\alpha \mathrm{COP}$; as well as those fed with dsGFP and ds $\alpha \mathrm{COP}$, both at 1 and $3 \mu \mathrm{g}$ dsRNA/ $\mu \mathrm{L}$. For each treatment group, three replicates of six beetles were used for gene expression analysis at $2 \mathrm{~d}$ post-treatment, and another three replicates of six beetles at $5 \mathrm{~d}$ post-treatment. Beetles to be analysed were placed in RNAlater RNA Stabilisation Solution (Thermo Fisher Scientific, Waltham, Massachusetts, USA), at their respective time point of interest, until analysis. RNA extraction was performed using an RNeasy mini kit (Qiagen, Hilden, Germany), and $200 \mathrm{ng}$ of RNA was used for quantifying relative gene expression (SOLIScript 1-step kit, Solis BioDyne, Tartu, Estonia). Cycle conditions, using QuantiStudio 5 Real-Time PCR System (Applied Biosystems, Foster City, California, USA), were: $50{ }^{\circ} \mathrm{C}$ for $15 \mathrm{~min}, 40$ cycles at $95{ }^{\circ} \mathrm{C}$ for $15 \mathrm{~s}, 58{ }^{\circ} \mathrm{C}$ for $60 \mathrm{~s}$, and ending with a melting curve analysis. Normalisation of the data was performed using the two reference genes ribosomal protein $S 3$ (rps3) and actin (act). Primer amplification efficiencies were determined via RNA dilution series (Online Resource 3). Relative gene expression values were calculated using the $2^{-\Delta \Delta \mathrm{Ct}}$ method (Livak and Schmittgen 2001). Comparisons between dsGFP and ds $\alpha \mathrm{COP}$ treatments, regarding relative gene expression, were statistically assessed for both microinjected and dsRNA-fed beetles using Welch's t-test in R software v1.1.463.

\section{Results}

\section{Survival of dsRNA-microinjected pollen beetles}

Direct microinjection of $\mathrm{ds} \alpha \mathrm{COP}$ resulted in a significant reduction in survival of $B$. aeneus (Fig. 2a, Online Resource 4). At $10 \mathrm{~d}$ post-injection, dsGFP-injected beetles showed $95 \%$ survival. In contrast, survival of ds $\alpha$ COP-injected beetles fell to $85 \%(p=0.03)$ after $2 \mathrm{~d}$, $60 \%(p<0.0001)$ after $4 \mathrm{~d}, 12.5 \%$ after $6 \mathrm{~d}$, and $0 \%$ after $10 \mathrm{~d}$ post-injection. Moreover, mortality of the ds $\alpha \mathrm{COP}$ injected beetles was often preceded by a loss of mobility (Online Resources 5, 6a).
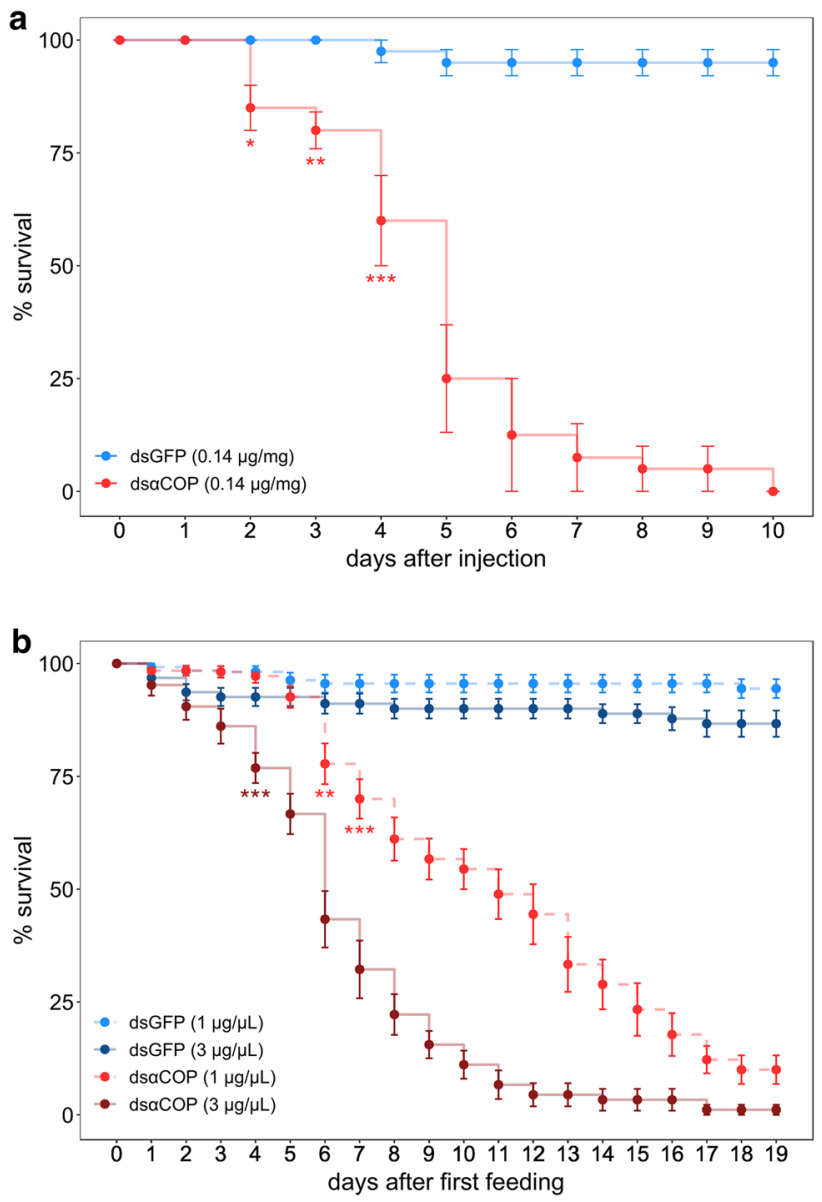

Fig.2 Survival curves, comparing ds $\alpha \mathrm{COP}$ treatments with their respective dsGFP controls, in microinjected (a) and dsRNA-fed (b) pollen beetles. Microinjection experiment: $n=40$ (4 replicates of 10 beetles) per treatment. Feeding experiment: $n=21$ ( 21 cages of 6 beetles; days 0-2), 18 (18 cages of 6 beetles; days 3-5) and 15 (15 cages of 6 beetles; days 6-19) per treatment. Microinjection data were analysed using Fisher's exact test (error bars: \pm SE). Feeding data were analysed using the Kruskal-Wallis test with post hoc Wilcoxon rank-sum test for pairwise comparisons (error bars: \pm SEM). Asterisks indicate significant differences between $\mathrm{ds} \alpha \mathrm{COP}$ and respective dsGFP treatments. $d f=3, *=p<0.05, * *=p<0.01, * * *=p<0.001$ 


\section{Survival of dsRNA-fed pollen beetles}

Dietary exposure to ds $\alpha \mathrm{COP}$, at both concentrations examined, resulted in significant reductions in B. aeneus survival (Fig. 2b, Online Resource 4). At $19 \mathrm{~d}$ after the start of the feeding experiment, we observed $95 \%$ survival in the dsGFP at $1 \mu \mathrm{g} / \mu \mathrm{L}$ treatment, and $87 \%$ survival in the dsGFP at $3 \mu \mathrm{g} /$ $\mu \mathrm{L}$ treatment. Beetles fed ds $\alpha \mathrm{COP}$ at $1 \mu \mathrm{g} / \mu \mathrm{L}$ showed significant mortality ( $78 \%$ survival, $d f=3, p=0.003$ ) $6 \mathrm{~d}$ after first exposure, followed by a steady decrease to $61 \%$ ( $8 \mathrm{~d}$, $d f=3, p<0.0001), 54 \%(10 \mathrm{~d}), 44 \%$ (12 d), 29\% (14 d), $18 \%$ (16 d), and $10 \%$ survival (18 d). Beetles fed ds $\alpha$ COP at $3 \mu \mathrm{g} / \mu \mathrm{L}$ showed significant mortality ( $77 \%$ survival; $d f=3$, $p=0.0007) 4 \mathrm{~d}$ after first exposure, survival here falling more rapidly, to $43 \%(d f=3, p<0.0001)$ after $6 \mathrm{~d}, 20 \%(8$ d), $11 \%(10 \mathrm{~d})$, and $1 \%(17 \mathrm{~d})$.

From $2 \mathrm{~d}$ after first exposure to ds $\alpha \mathrm{COP}$, we observed significantly lower survival in the $3 \mu \mathrm{g} / \mu \mathrm{L}$ than in the $1 \mu \mathrm{g} / \mu \mathrm{L}$ treatment $(2 \mathrm{~d} p=0.014,3 \mathrm{~d} p=0.0085,4-12 \mathrm{~d} p<0.0001$, $13-14 \mathrm{~d} p=0.0002,15 \mathrm{~d} p=0.0033,16 \mathrm{~d} p=0.009,17 \mathrm{~d}$ $p=0.002,18-19 \mathrm{~d} p=0.015, d f=3)$.

Blue faeces were observed extensively throughout all cages from each treatment, providing further indication that the beetles fed on their respective treatments. Similar to ds $\alpha C O P$-injected beetles, mortality of the ds $\alpha \mathrm{COP}$-fed beetles was often preceded by a loss of mobility (Online Resources 5, 6b).

\section{Effect on aCOP expression}

As shown in Fig. 3, the obtained qPCR results indicated that $\alpha C O P$ was downregulated by the dsRNA targeting this gene when delivered by microinjection and feeding. The ds $\alpha$ COP-injected beetles $(t=7.56, d f=3.19, p=0.0038)$ and the beetles that fed on the ds $\alpha \mathrm{COP}$ at $1 \mu \mathrm{g} / \mu \mathrm{L}(t=2.38$, $d f=2.65, p=0.109$ ) showed a respective mean reduction in expression of the target gene of $82 \%$ and $52 \%$ after $5 \mathrm{~d}$, compared to respective dsGFP controls. In contrast, at the shorter time point of $2 \mathrm{~d}$, there was no apparent reduction in relative expression of $\alpha C O P$ (microinjection: $p=0.67$; feeding $1 \mu \mathrm{g} / \mu \mathrm{L}: p=0.44)$. In addition, with the higher ds $\alpha \mathrm{COP}$ concentration of $3 \mu \mathrm{g} / \mu \mathrm{L}$ by feeding, the reduction in relative expression of $\alpha C O P$ was minor, with only $36 \%$ mean reduction at $2 \mathrm{~d}(t=1.87, d f=2.88, p=0.16)$, and $15 \%$ at 5 $\mathrm{d}(t=1.24, d f=3.60, p=0.29)$.

\section{Discussion}

\section{aCOP is an effective RNAi target in Brassicogethes aeneus}

We provide laboratory evidence suggesting that $\alpha C O P$ is an effective RNAi target in B. aeneus, as mortality in B. aeneus was highly significant after dietary exposure to both concentrations of ds $\alpha \mathrm{COP}$, confirming $B$. aeneus's sensitivity to RNAi via dietary exposure to ds $\alpha \mathrm{COP}$, which is in agreement with Knorr et al. (2018). We believe that the high mortality in our B. aeneus RNAi assays, especially for microinjection, was caused by gene silencing of the target gene, $\alpha C O P$. Indeed, in ds $\alpha \mathrm{COP}$-injected beetles, we observed a significant reduction in $\alpha C O P$ mRNA $5 \mathrm{~d}$ after treatment.

While we observed high $B$. aeneus mortality rates, yet did not detect corresponding significant $\alpha C O P$ silencing in beetles that fed upon ds $\alpha \mathrm{COP}$, previous research has shown that relative gene expression does not always

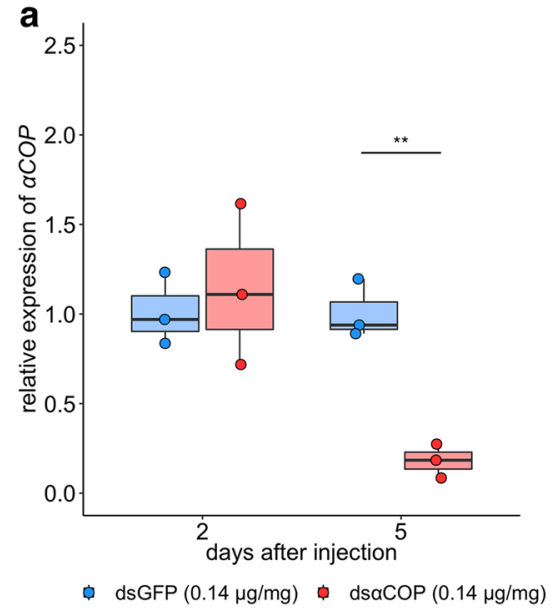

Fig.3 Relative gene expression of $\alpha C O P$ in microinjected (a) and dsRNA-fed (b) pollen beetles, at 2 and $5 \mathrm{~d}$ after treatment. Data were normalised using the reference genes rps 3 and act. $n=3$ (3 replicates of 6 beetles) for each time point of analysis within each treat-

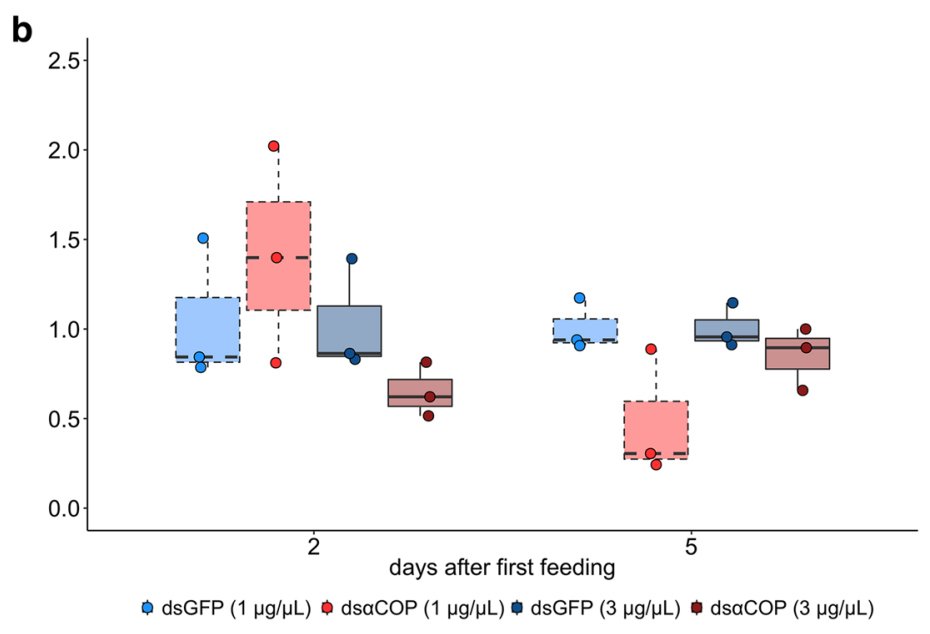

ment. Relative gene expression values were calculated using the $2^{-\Delta \Delta \mathrm{Ct}}$ method. Statistical comparisons were made using Welch's $t$-test. Asterisks indicate significant differences between ds $\alpha \mathrm{COP}$ and respective dsGFP treatments. $* *=p<0.01$ 
reflect protein levels (Michel et al. 2005; Scott et al. 2013). There were indeed samples indicating downregulation of $\alpha C O P$ in ds $\alpha C O P$-fed beetles; however, high variability resulted in non-significant qPCR results for these treatments. Several factors may play a role in the variability and differences we observed. A decrease in $\alpha C O P$ mRNA and protein levels could, through a feedback mechanism, stimulate the overexpression of $\alpha C O P$, making it difficult to detect significant changes at the transcript level while the protein level is decreasing during $B$. aeneus's exposure to ds $\alpha \mathrm{COP}$; the decreased $\alpha \mathrm{COP}$ protein level ultimately leading to $B$. aeneus mortality. Furthermore, an inferior gene silencing effect was observed with respect to feeding, compared to microinjection. This could be related to the requirement for crossing an additional physiological barrier, for example, that of the midgut epithelium; and/or maintaining dsRNA stability in the midgut lumen, where a much higher concentration of dsRNA-degrading nucleases are present, compared to that which is found in the haemolymph (Peng et al. 2018). In addition, we performed qPCR on whole insects; and microinjection may have spread the exogenous dsRNA to more tissues than via dietary exposure to dsRNA. Future studies should consider extracting RNA from gut tissue for the evaluation of target gene silencing following dsRNA feeding treatments, in contrast to whole body samples where the overall gene silencing effect could be diluted.

Targeting COPI genes via RNAi has been performed in several agricultural pest insect studies. The results of nearly $100 \%$ mortality, post-microinjection of dsRNA targeting $\alpha C O P$, has suggested the potential efficacy of targeting this gene in both $C$. brunneus (Christiaens et al. 2016) and C. puncticollis (Prentice et al. 2017). Taning et al. (2016) observed significant gene silencing and subsequent mortality (46 $\pm 9 \%$ ) when targeting $\alpha C O P$ via microinjection of dsRNA in spotted wing drosophila (Drosophila suzukii Matsumura) adults, though less effective gene silencing and mortality effects through dietary exposure to dsRNA targeting this gene in both larvae and adults. Lastly, another COPI subunit, coatomer subunit beta $(\beta C O P)$, is a suitable target in several agricultural pests (Baum et al. 2007; Kwon et al. 2013; Mao et al. 2015; Rodrigues et al. 2017; Shin et al. 2020).

The present study further indicates a concentrationdependent effect of ds $\alpha \mathrm{COP}$ on $B$. aeneus survival, where the higher feeding concentration ds $\alpha$ COP treatment resulted in significant mortality $2 \mathrm{~d}$ earlier than the lower concentration, as well as a steeper mortality rate compared to that of the lower concentration. Rodrigues et al. (2017) also observed a concentration-dependent effect of exogenous dsRNA on mortality when targeting $\beta C O P$.

\section{Future steps towards application}

While a $6 \mathrm{~d}$ time-to-effect is less than ideal for field use as an insecticide, an RNAi approach cannot be expected to cause mortality as quickly as some other (e.g. neurotoxic) insecticides; turnover time of the target protein will remain a limiting factor. However, there remains the possibility to improve efficacy and speed via co-formulants (e.g. nanoparticles) that enhance efficiency of both dsRNA uptake and subsequent RNAi (Christiaens et al. 2020; Yan et al. 2020). The benefits of this technology lie in the associated biosafety aspects, due to its mode of action. Ideally, an RNAi approach should be used in combination with other ecologically sustainable approaches (e.g. conservation biocontrol), in an integrated pest management context, for maximum benefit.

There are various application methods for effective dsRNA-based control of agricultural pest insects, and the most suitable method is always species-dependent. It is possible that the most effective method of $B$. aeneus control in oilseed rape crops is via the use of an RNAi cultivar expressing dsRNA in nectar and pollen. This method would allow the crop to continuously produce dsRNA, preferably in the plant parts on which B. aeneus feeds. While current restrictions prevent the implementation of this technology within EU countries, this could change with further experience with the technology, and understanding of its impacts (e.g. after refinements are made to RNAi risk assessments) (Arpaia et al. 2020). There may also be the possibility to apply appropriately timed dsRNA-based spray treatments to effectively manage $B$. aeneus. The exploitation of exogenous dsRNA-based biocontrol compounds, for application within a wide variety of crop-pest systems, is an expanding and momentous field of interest, and likely has both a prominent and practicable place in the nearing future's crop protection market (Taning et al. 2019; Mezzetti et al. 2020). Field-realistic experiments simulating dietary exposure to dsRNAs are required with regard to B. aeneus, and should include examining the effect of spraying dsRNA-based treatments onto both bud and flower clusters of oilseed rape. The bud stage is oilseed rape's most vulnerable period, as adult bud feeding and oviposition by B. aeneus, as well as larval bud feeding, can result in considerable yield losses. At the same time, targeting both adults and larvae that feed on nectar and pollen of open flowers could reduce the abundance of overwintering $B$. aeneus, potentially reducing yield losses in the following growing season. Thus far, only $B$. aeneus adults have been examined for efficacy of RNAi; future dietary exposure studies should include $B$. aeneus larvae. Furthermore, as B. aeneus is one of several major pests of oilseed rape in Europe, future studies should explore the potential for RNAi-based management of other oilseed rape pests as well, and the prospect of targeting multiple 
jointly-present oilseed rape pests simultaneously via stacked dsRNA treatments.

Dietary exposure to dsRNA is not the only potential dsRNA uptake method for effective control of agricultural pest insects. RNAi via topical exposure to dsRNA has been observed in some hemipteran insects, including the pea aphid (Acyrthosiphon pisum Harris), green peach aphid (Myzus persicae Sulzer) and brown citrus aphid (Toxoptera citricida, formerly Toxoptera citricidus and Aphis citricidus Kirkaldy) (Niu et al. 2019). B. aeneus is a good candidate for testing RNAi via topical exposure to dsRNA, especially in larvae, which have a soft unsclerotised cuticle, although the body of adult $B$. aeneus also has soft regions that are potentially vulnerable to topical exposure to dsRNAs. Candidate methods for testing the effect of topical exposure to dsRNAs on $B$. aeneus include administering submicron amounts of dsRNA-based treatments directly onto the bodies of larval and adult $B$. aeneus, and miniature-scale dsRNA soil drench experiments examining the potential impact on soil-inhabiting second instar larval- and pupating $B$. aeneus.

\section{Conclusion}

The requirement of nucleotide sequence complementarity makes dsRNA-based biopesticides likely the most selective pesticides known to date, since they potentially affect only the target pest, and no other organisms, resulting in a more ecologically sustainable method of control; though this method of control would require the application of multiple dsRNAs in the event of managing multiple pest insect species. We showed that $\alpha C O P$ represents an effective RNAi target in the oilseed rape pest $B$. aeneus. We observed significant gene silencing-induced mortality via both microinjection and feeding of ds $\alpha \mathrm{COP}$, confirming $B$. aeneus's sensitivity to ds $\alpha \mathrm{COP}$ via both routes of exposure. This work represents the first study to demonstrate highly significant gene silencing-induced mortality in an agricultural pest through dietary exposure to dsRNA targeting a COPI gene. Thus, future studies towards the application of RNAi in $B$. aeneus management should examine $\alpha C O P$ alongside other RNAi targets previously shown to be associated with high levels of gene silencing and subsequent mortality in B. aeneus. Next steps include examining additional routes of exposure to dsRNAs, particularly within a field-realistic context.

\section{Author contributions}

JW, CNTT, OC, GLL, GS, and EV conceived the study. JW, CNTT, KP, and EV designed the method. JW and SS performed the study. JW and AIS analysed data and prepared figures. JW wrote the original draft. JW, CNTT, AIS, OC, KP, GLL, GS, and EV contributed revisions to subsequent drafts. All authors read and approved the manuscript.

Acknowledgements We thank the owners of the land on which pollen beetles were collected for this study, and a member of the Estonian University of Life Sciences' Chair of Plant Breeding and Plant Biology for molecular support. Jonathan Willow is the recipient of a $\mathrm{PhD}$ grant from the European Social Fund for Doctoral Students, as well as the Internationalisation Programme DoRa (carried out by the Archimedes Foundation). Olivier Christiaens is a recipient of a postdoctoral fellowship from the Research Foundation-Flanders (FWO-Vlaanderen). The authors acknowledge financial support from the institutional Research Funding project no IUT36-2 of the Estonian Research Council, the European ERA-NET C-IPM project "IPM4Meligethes" (Project No 3G0H0416), the Special Research Fund (BOF) of Ghent University and the Research Foundation-Flanders (FWO-Vlaanderen).

Funding This study was partially funded by the institutional Research Funding project no IUT36-2 of the Estonian Research Council, the European ERA-NET C-IPM project "IPM4Meligethes" (Project No 3G0H0416), the Special Research Fund (BOF) of Ghent University and the Research Foundation-Flanders (FWO-Vlaanderen). The funders had no role in study design, data collection and analysis, decision to publish, or preparation of the manuscript.

Availability of data and material Datasets related to the present study are available upon reasonable request from the corresponding author.

\section{Compliance with ethical standards}

Conflicts of interest The authors declare no conflicts of interest.

Consent to participate Consent was given by all participants included in the study.

Consent for publication All authors consent to the publication of this manuscript in Journal of Pest Science.

Ethical approval This study does not contain any experiments using any animal species that requires ethical approval.

Open Access This article is licensed under a Creative Commons Attribution 4.0 International License, which permits use, sharing, adaptation, distribution and reproduction in any medium or format, as long as you give appropriate credit to the original author(s) and the source, provide a link to the Creative Commons licence, and indicate if changes were made. The images or other third party material in this article are included in the article's Creative Commons licence, unless indicated otherwise in a credit line to the material. If material is not included in the article's Creative Commons licence and your intended use is not permitted by statutory regulation or exceeds the permitted use, you will need to obtain permission directly from the copyright holder. To view a copy of this licence, visit http://creativecommons.org/licenses/by/4.0/.

\section{References}

Abdourahime H, Anastassiadou M, Arena M et al (2019) Peer review of the pesticide risk assessment of the active substance thiacloprid. EFSA J 17:e05595. https://doi.org/10.2903/j.efsa.2019.5595 
Arpaia S, Christiaens O, Giddings K et al (2020) Biosafety of GM crop plants expressing dsRNA: data requirements and EU regulatory considerations. Front Plant Sci. https://doi.org/10.3389/ fpls.2020.00940

Baum JA, Bogaert T, Clinton W et al (2007) Control of coleopteran insect pests through RNA interference. Nat Biotechnol 25:13221326. https://doi.org/10.1038/nbt1359

Beck R, Ravet M, Wieland FT, Cassel D (2009) The COPI system: molecular mechanisms and function. FEBS Lett 583:2701-2709. https://doi.org/10.1016/j.febslet.2009.07.032

Beller M, Sztalryd C, Southall N et al (2008) COPI complex is a regulator of lipid homeostasis. PLOS Biol. https://doi.org/10.1371/ journal.pbio.0060292

Berheim EH, Jenks JA, Lundgren JG et al (2019) Effects of neonicotinoid insecticides on physiology and reproductive characteristics of captive female and fawn white-tailed deer. Sci Rep 9:1-10. https://doi.org/10.1038/s41598-019-40994-9

Bramlett M, Plaetinck G, Maienfisch P (2019) RNA-based biocontrols-a new paradigm in crop protection. Engineering. https:// doi.org/10.1016/j.eng.2019.09.008

Calvo-Agudo M, González-Cabrera J, Picó Y et al (2019) Neonicotinoids in excretion product of phloem-feeding insects kill beneficial insects. Proc Natl Acad Sci 116:16817-16822. https ://doi.org/10.1073/pnas.1904298116

Christiaens O, Prentice K, Pertry I et al (2016) RNA interference: a promising biopesticide strategy against the African sweetpotato weevil Cylas brunneus. Sci Rep 6:1-11. https://doi.org/10.1038/ srep38836

Christiaens O, Petek M, Smagghe G, Taning CNT (2020) The use of nanocarriers to improve the efficiency of RNAi-based pesticides in agriculture. In: Fraceto LF, SS de Castro VL, Grillo R, et al. (eds) Nanopesticides. Springer International Publishing, Berlin

European Commission (2018) Public consultation on the active substance thiacloprid. In: Eur. Food Saf. Auth. https://www.efsa. europa.eu/en/consultations/call/180123. Accessed 28 Jun 2020

Gibbons D, Morrissey C, Mineau P (2015) A review of the direct and indirect effects of neonicotinoids and fipronil on vertebrate wildlife. Environ Sci Pollut Res 22:103-118. https://doi. org/10.1007/s11356-014-3180-5

Heimbach U, Müller A (2013) Incidence of pyrethroid-resistant oilseed rape pests in Germany. Pest Manag Sci 69:209-216. https ://doi.org/10.1002/ps.3351

Huvenne H, Smagghe G (2010) Mechanisms of dsRNA uptake in insects and potential of RNAi for pest control: a review. J Insect Physiol 56:227-235. https://doi.org/10.1016/j.jinsp hys.2009.10.004

Jans D (2012) Toxicity to the parasitoid wasp Aphidius rhopalosiphi (DeStephani-Perez) (Hymenoptera: Braconidae) using an extended laboratory test with aged residues on maize-thiacloprid OD 240 g/L-final report. European Commission. Renewal Assessment Report prepared according to the Commission Regulation (EU) N ${ }^{\circ}$ 1107/2009. Vol 3-B.9 (PPP)-Thiacloprid OD 240 (240 g/L. 2017: 262-6. https://www.efsa.europa.eu/en/ consultations/call/180123

Kaiser C, Jensen K-MV, Nauen R, Kristensen M (2018) Susceptibility of Danish pollen beetle populations against $\lambda$-cyhalothrin and thiacloprid. J Pest Sci 91:447-458. https://doi.org/10.1007/ s10340-017-0856-x

Kirk-Spriggs AH (1996) Pollen Beetles - Coleoptera: Kateretidae and Nitidulidae: Meligethinae. Royal Entomological Society, London

Kitazawa D, Yamaguchi M, Mori H, Inoue YH (2012) COPI-mediated membrane trafficking is required for cytokinesis in Drosophila male meiotic divisions. J Cell Sci 125:3649-3660. https://doi. org/10.1242/jcs. 103317
Knorr E, Fishilevich E, Tenbusch L et al (2018) Gene silencing in Tribolium castaneum as a tool for the targeted identification of candidate RNAi targets in crop pests. Sci Rep 8:1-15. https://doi. org/10.1038/s41598-018-20416-y

Kwon DH, Park JH, Lee SH (2013) Screening of lethal genes for feeding RNAi by leaf disc-mediated systematic delivery of dsRNA in Tetranychus urticae. Pestic Biochem Physiol 105:69-75. https:// doi.org/10.1016/j.pestbp.2012.12.001

Livak KJ, Schmittgen TD (2001) Analysis of relative gene expression data using real-time quantitative PCR and the $2^{-\Delta \Delta C t}$ method. Methods 25:402-408. https://doi.org/10.1006/meth.2001.1262

Mao J, Zhang P, Liu C, Zeng F (2015) Co-silence of the coatomer $\beta$ and $v$-ATPase $A$ genes by siRNA feeding reduces larval survival rate and weight gain of cotton bollworm, Helicoverpa armigera. Pestic Biochem Physiol 118:71-76. https://doi.org/10.1016/j.pestb p.2014.11.013

Mauchline AL, Hervé MR, Cook SM (2018) Semiochemical-based alternatives to synthetic toxicant insecticides for pollen beetle management. Arthropod-Plant Interact 12:835-847. https://doi. org/10.1007/s11829-017-9569-6

Mezzetti B, Smagghe G, Arpaia S et al (2020) RNAi: what is its position in agriculture? J Pest Sci. https://doi.org/10.1007/s1034 0-020-01238-2

Michel K, Budd A, Pinto S et al (2005) Anopheles gambiae SRPN2 facilitates midgut invasion by the malaria parasite Plasmodium berghei. EMBO Rep 6:891-897. https://doi.org/10.1038/sj.embor .7400478

Niu J, Yang W-J, Tian Y et al (2019) Topical dsRNA delivery induces gene silencing and mortality in the pea aphid. Pest Manag Sci 75:2873-2881. https://doi.org/10.1002/ps.5457

Peng Y, Wang K, Fu W et al (2018) Biochemical comparison of dsRNA degrading nucleases in four different insects. Front Physiol 9:624. https://doi.org/10.3389/fphys.2018.00624

Pisa L, Goulson D, Yang E-C et al (2017) An update of the Worldwide Integrated Assessment (WIA) on systemic insecticides. part 2: impacts on organisms and ecosystems. Environ Sci Pollut Res. https://doi.org/10.1007/s11356-017-0341-3

Prentice K, Christiaens O, Pertry I et al (2017) RNAi-based gene silencing through dsRNA injection or ingestion against the African sweet potato weevil Cylas puncticollis (Coleoptera: Brentidae). Pest Manag Sci 73:44-52. https://doi.org/10.1002/ps.4337

Raimets R, Bontšutšnaja A, Bartkevics V et al (2020) Pesticide residues in beehive matrices are dependent on collection time and matrix type but independent of proportion of foraged oilseed rape and agricultural land in foraging territory. Chemosphere 238:124555. https://doi.org/10.1016/j.chemosphere.2019.124555

Rodrigues TB, Rieske LKJ, Duan et al (2017) Development of RNAi method for screening candidate genes to control emerald ash borer Agrilus planipennis. Sci Rep 7:7379. https://doi.org/10.1038/ s41598-017-07605-x

Scott JG, Michel K, Bartholomay LC et al (2013) Towards the elements of successful insect RNAi. J Insect Physiol 59:1212-1221. https ://doi.org/10.1016/j.jinsphys.2013.08.014

Seidenglanz M, Poslušná J, Kolařík P et al (2017) Negative correlations between the susceptibilities of Czech and Slovak pollen beetle populations to lambda-cyhalothrin and chlorpyrifos-ethyl in 2014 and 2015. Plant Prot Sci 53:108-117. https://doi.org/10.17221 /187/2015-PPS

Shin YH, Lee SH, Park Y-D (2020) Development of mite (Tetranychus urticae)-resistant transgenic Chinese cabbage using plant-mediated RNA interference. Hortic Environ Biotechnol 61:305-315. https://doi.org/10.1007/s13580-019-00203-y

Slater R, Ellis S, Genay J-P et al (2011) Pyrethroid resistance monitoring in European populations of pollen beetle (Meligethes spp.): a coordinated approach through the Insecticide Resistance Action 
Committee (IRAC). Pest Manag Sci 67:633-638. https://doi. org/10.1002/ps.2101

Stará J, Kocourek F (2018) Seven-year monitoring of pyrethroid resistance in the pollen beetle (Brassicogethes aeneus F.) during implementation of insect resistance management. Pest Manag Sci 74:200-209. https://doi.org/10.1002/ps.4695

Sugiyama K, Katayama H, Saito T (2011) Effect of insecticides on the mortalities of three whitefly parasitoid species, Eretmocerus mundus, Eretmocerus eremicus and Encarsia formosa (Hymenoptera: Aphelinidae). Appl Entomol Zool 46:311-317. https://doi. org/10.1007/s13355-011-0044-z

Taning CNT, Christiaens O, Berkvens N et al (2016) Oral RNAi to control Drosophila suzukii: laboratory testing against larval and adult stages. J Pest Sci 89:803-814. https://doi.org/10.1007/s1034 0-016-0736-9

Taning CN, Arpaia S, Christiaens O et al (2019) RNA-based biocontrol compounds: current status and perspectives to reach the market. Pest Manag Sci. https://doi.org/10.1002/ps.5686

Willow J, Silva A, Veromann E, Smagghe G (2019) Acute effect of low-dose thiacloprid exposure synergised by tebuconazole in a parasitoid wasp. PLoS ONE. https://doi.org/10.1371/journ al.pone. 0212456

Wu C-H, Lin C-L, Wang S-E, Lu C-W (2019) Effects of imidacloprid, a neonicotinoid insecticide, on the echolocation system of insectivorous bats. Pestic Biochem Physiol. https://doi.org/10.1016/j. pestbp.2019.10.010
Yan S, Ren B-Y, Shen J (2020) Nanoparticle-mediated double-stranded RNA delivery system: a promising approach for sustainable pest management. Insect Sci. https://doi.org/10.1111/1744-7917.12822

Zamojska J (2017) Differences in susceptibility of the cabbage seed weevil (Ceutorchynhus assimilis Payk.) (Coleoptera: Curculionidae) and the pollen beetle (Meligethes aeneus F.) (Coleoptera: Nitidulidae) to indoxacarb and deltamethrin and resistance mechanisms of the cabbage seed weevil to indoxacarb. Phytoparasitica 45:407-418. https://doi.org/10.1007/s12600-017-0588-8

Zhang H, Breeze T, Bailey A et al (2017) Arthropod pest control for UK oilseed rape-comparing insecticide efficacies, side effects and alternatives. PLoS ONE 12:e0169475. https://doi.org/10.1371/ journal.pone. 0169475

Zhu KY, Palli SR (2020) Mechanisms, applications, and challenges of insect RNA interference. Annu Rev Entomol 65:293-311. https ://doi.org/10.1146/annurev-ento-011019-025224

Zimmer CT, Maiwald F, Schorn C et al (2014) A de novo transcriptome of European pollen beetle populations and its analysis, with special reference to insecticide action and resistance. Insect Mol Biol 23:511-526. https://doi.org/10.1111/imb.12099

Publisher's Note Springer Nature remains neutral with regard to jurisdictional claims in published maps and institutional affiliations. 